\title{
The mirage of universality: Canada's failure to act on social policy and health care
}

\author{
Andrew Boozary MD MPP, Andreas Laupacis MD MSc
}

- Cite as: CMAJ 2020 February 3;192:E105-6. doi: 10.1503/cmaj.200085

See related article at www.cmaj.ca/lookup/doi/10.1503/cmaj.190517

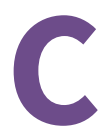
anadians pride themselves on the fairness of their society and their health care system, yet disturbing inequities persist in both. For example, between 1993 and 2014, the likelihood of dying from a preventable cause increased more than twofold when comparing Ontario's poorest and most affluent neighbourhoods. ${ }^{1}$ These differences come with the human cost of thousands of avoidable deaths every year and are particularly harrowing for Indigenous Peoples. The persistence of these disparities amounts to discrimination against Canada's most disadvantaged populations. It is well past time that we act on the undeniable importance of the social determinants of health and remedy the inequities within the health care system itself.

The problem is both wicked and multifaceted. First, the relation between income and health is bidirectional. Poverty is associated with many health risks tied to social context such as housing insecurity, psychological and social isolation, unhealthy food options, trauma, injury and substance use disorders.

Second, medicare in Canada covers only certain services. Prescription drugs, mental health counselling, the bulk of home care, physiotherapy and other services are not consistently publicly insured. Many people with lower incomes cannot afford them and end up in emergency departments and hospital wards with problems that might have been mitigated earlier or prevented altogether.

Third, even when services are publicly funded, disadvantaged patients with limited financial resources use fewer preventive and outpatient services than those with higher incomes. Poverty imposes insidious barriers even when services are "free."

The solutions to these pathologies of poverty also need to be multifaceted.

When compared with our international peers, Canada ranked last on the amount we spent on social programs in $2017 .{ }^{2}$ Canada needs to invest in, and evaluate, new social programs such as a guaranteed annual income. The arbitrary silos between health and social services must be reconsidered, with an emphasis on health and well-being in addition to conventional metrics such as gross domestic product growth. ${ }^{3}$ Our policy-makers might look to New Zealand, where earlier this year its government released a "well-being budget" with substantial investments in mental health, Indigenous Peoples and poverty reduction. ${ }^{4}$ Iceland and Scotland have articulated an interest in similar policies. ${ }^{5}$ Even the United States recently proposed a national interagency council on the social determinants of health. ${ }^{6}$ The effects of these strategies are not yet known, but if specific components are carefully evaluated, Canada can learn from them.

Canadians have universal access to publicly funded physician and hospital care; however, access to much of health care still depends on a person's income. The costs of medicines and the lack of publicly funded psychotherapy, for instance, are excluding millions of Canadians from evidence-based treatments. ${ }^{7}$ New investments that expand public provisions of health care are urgently needed.

The effects of a fraying social safety net are pouring into the health care sector. In response, several health care organizations are attempting to tackle the unmet social needs of their patients through social prescribing, that is, offering community supports for issues ranging from food insecurity to affordable and safe housing. It is commendable of the health care sector to address patients' social needs that are largely under the purview of municipal, provincial and federal governments. But this will not be sustainable nor sufficient alone, and the health care system itself has work to do.

The system can no longer overlook the serious disparities that exist even when there are no direct financial barriers to access. In Ontario, for example, a 2016 study found that only $54 \%$ of women living in the poorest neighbourhoods completed cervical cancer screening compared with more than $67 \%$ of women living in the most affluent urban neighbourhoods. ${ }^{8} \mathrm{~A}$ similar social gradient also applied for colorectal cancer screening. In addition, where there have been investments to improve primary care capacity, access increased disproportionately for those living in the richest neighbourhoods. ${ }^{9}$ Tacit acceptance of such inequities should not be allowed to continue.

Human insights need to be central in the way health care is designed and delivered. Integrating social context will require partnering with disadvantaged patients and communities to better understand the challenges they face and, together, codesigning meaningful solutions that help empower and drive the outcomes that matter most to them. 
Just like the evidence-based standards expected for drugs or therapeutics, changes in the delivery of health care must be rigorously evaluated. In the Financial Accountability Office of Ontario's most recent analysis, the Ontario Ministry of Health and Long-term Care is projected to spend $\$ 63.5$ billion in 2019-2020, with only $0.03 \%$ of that directed to health system research. ${ }^{10}$ Such a meager investment in policy evaluation implies faith that providers and policy-makers already know what works best. We do not share that faith - true innovation requires investment in experimentation and evaluation.

This leaves the question that can no longer be shirked: should Canadians living in low-income areas have the same chance of avoiding preventable disease or death as those living in affluent ones? The inaction to date has been punishing. What is needed now is public investment, co-designed innovation and political will.

\section{References}

1. Zygmunt A, Kendall CE, James $\mathrm{P}$, et al. Avoidable mortality rates decrease but inequity gaps widen for marginalized neighborhoods: a population-based analysis in Ontario, Canada from 1993 to 2014. J Community Health 2019;Dec 9 [Epub ahead of print]. doi: 10.1007/s10900-019-00778-8. .

2. Papanicolas I, Woskie LR, Jha AK. Health care spending in the United States and other high-income countries. JAMA 2018;319:1024-39.

3. Tonelli M, Tang KC, Forest PG. Canada needs a "Health in All Policies" action plan now. CMAJ 2020;192:E61-7.

4. Anderson M, Mossialos E. Beyond gross domestic product for New Zealand's wellbeing budget. Lancet Public Health 2019;4:e320-1.
5. Gregory A. Governments should put wellbeing of citizens ahead of GDP in budget priorities, Iceland PM urges. The Independent 2019 Dec 4. Available: www. independent.co.uk/news/world/europe/iceland-gdp-wellbeing-budget-climate -change-new-zealand-arden-sturgeon-a9232626.html (accessed 2020 Jan. 4).

6. H.R.4004 - Social Determinants Accelerator Act of 2019 (116th US Congress). Available: www.congress.gov/bill/116th-congress/house-bill/4004?s=1\&r= (accessed 2020 Jan. 4).

7. Law MR, Cheng L, Dhalla IA, et al. The effect of cost on adherence to prescription medications in Canada. CMAJ 2012;184:297-302.

8. Income and health: opportunities to achieve health equity in Ontario. Toronto: Health Quality Ontario; 2016. Available: www.hqontario.ca/Portals/0/documents/ system-performance/health-equity-report-en.pdf (accessed 2020 Jan. 21).

9. Glazier RH, Kopp A, Schultz SE, et al. All the right intentions but few of the desired results: lessons on access to primary care from Ontario's patient enrolment models. Healthc Q 2012;15:17-21.

10. Expenditure estimates 2019-20: Ministry of Health and Long-Term Care. Toronto: Financial Accountability Office of Ontario; 2019. Available: www.fao-on .org/en/Blog/Publications/estimates-health-2019\#Health\%20Policy\%20and\%20 Research\%20Program (accessed 2019 Dec. 29).

Competing interests: See www.cmaj.ca/site/misc/cmaj_staff.xhtml. No other competing interests were declared.

Affiliations: Editor-in-Chief, CMAJ (Laupacis); Dalla Lana School of Public Health (Boozary), University of Toronto, Toronto, Ont.; Health and Social Policy (Boozary), University Health Network, Toronto, Ont.; and Harvard T.H. Chan School of Public Health (Boozary), Boston, Mass.

Correspondence to: CMAJ editor, cmaj@cmajgroup.ca 